\title{
CHRONIC CONSTIPATION - the role of clinical assessment and colorectal physiologic tests to obtain an etiologic diagnosis
}

\author{
Antônio LACERDA-FILHO'1,2, Marcílio José Rodrigues LIMA'1, Marisa Fonseca MAGALHÃES ${ }^{1}$, \\ Rodrigo de Almeida PAIVA ${ }^{1}$ and José Renan da CUNHA-MELO', ${ }^{1,2}$
}

\begin{abstract}
Background - Diagnosis of subtypes of chronic constipation has been considered difficult to achieve even in specialized centers. Although colorectal physiologic tests have brought an important contribution, it remains unclear in which patients these tests should be indicated for. Aims - This study aims to establish a differential diagnosis for chronic constipation cases using clinical assessment and physiologic tests and to identify clinical parameters that could predict which patients need physiologic tests. Methods - One hundred and seventy nine patients $(83 \%$ females; mean age, 45$)$ with chronic constipation according to Rome II criteria were initially treated by dietary advice and functional reeducation and those unresponsive (110 or $61.5 \%$ ) were submitted to colonic transit time, defecography, anorectal manometry and electromyography, as needed. Results - A differential diagnosis was achieved in $63.6 \%$ of patients tested. However, $61.5 \%$ of 179 patients with chronic constipation (69 with no need to tests and 40 with normal tests) have etiologic diagnosis established only on clinical basis. Irritable bowel syndrome (32\%), pelvic floor dysfunction (29\%) and functional constipation due to faulty diet and life style habits $(22 \%)$ were the main causes of chronic constipation. Alternating constipation and nausea/vomiting were symptoms significantly related to the diagnosis of irritable bowel syndrome; younger age, larger intervals between bowel movements, occurrence of fecal impaction and necessity of enema were related to the diagnosis of non-chagasic megacolon and digital assistance to evacuate and large rectocele or spastic pelvic floor on rectal exam were associated to pelvic floor dysfunction. Patients with long-standing constipation, fecal impaction, abdominal pain not eased after defecation, necessity for enemas, digital assistance and evidence of rectocele tended to be in need for physiologic tests to define the cause of chronic constipation. Conclusions - The etiologic diagnosis of chronic constipation can be achieved in most of patients on a clinical basis and some symptoms may be significantly related to specific diagnoses. Indications for physiologic tests should be based on specific clinical parameters.
\end{abstract}

HEADINGS - Constipation. Irritable bowel syndrome. Defecation. Gastrointestinal transit.

\section{INTRODUCTION}

Chronic constipation (CC) may be defined, according to Rome II criteria, as an individual functional disorder - chronic functional constipation (FC) - or as part of irritable bowel syndrome (IBS), when abdominal pain or discomfort is present and related to symptoms of constipation (IBS constipation-predominant) ${ }^{(20)}$. Twenty percent of the populations of western countries are estimated to be affected. The symptoms impair the quality of life, causing CC to become an important health problem ${ }^{(7)}$. A number of CC patients usually complain of some kind of abdominal discomfort ${ }^{(18)}$, making the distinction between FC and IBS patients controversial and arbitrary. This makes the etiologic diagnosis of CC difficult, even in specialized centers. Although colorectal physiologic tests have brought an important contribution to clarify the final diagnosis of
$\mathrm{CC}$, it remains unclear in which patients these tests should be indicated for.

The aims of the present study were: (1) to establish etiologic diagnosis of $\mathrm{CC}$ cases and to differentiate patients with FC and IBS constipation-predominant assessed by Rome II criteria and by physiologic tests, when indicated, and (2) to predict which patients with CC need colorectal physiologic tests for etiologic diagnosis.

\section{METHODS}

\section{Patients}

One hundred and seventy-nine patients with chronic functional constipation were retrospectively selected among a total of 245 constipated patients referred to the Disorders of Defecation Outpatient Clinic, Alfa Institute of Gastroenterology, Federal University of Minas Gerais, Belo Horizonte, MG, Brazil, for investigation and treatment, 
from July 1998 to July 2002. Chronic functional constipation was defined according to Rome II Criteria ${ }^{(1)}$, for both primary FC and IBS with predominance of constipation (Figure 1).

\begin{tabular}{|c|}
\hline Chronic functional constipation (FC) \\
\hline $\begin{array}{l}\text { Two or more of the following for at least } 12 \text { weeks (not necessarily consecutive) in the } \\
\text { preceding } 12 \text { months: } \\
\text { - Straining during }>25 \% \text { of bowel movements } \\
\text { - Lumpy or hard stools for }>25 \% \text { of bowel movements } \\
\text { - Sensation of incomplete evacuation for }>25 \% \text { of bowel movements } \\
\text { - } \text { Manual maneuvers to facilitate }>25 \% \text { of bowel movements (e.g., digital } \\
\text { evacuation or support of the pelvic floor) } \\
\text { - Three bowel movements per week } \\
>\quad \text { Loose stools not present, and insufficient criteria for irritable bowel } \\
\text { syndrome met }\end{array}$ \\
\hline Irritable bowel syndrome constipation-predominant (IBS) \\
\hline $\begin{array}{l}\text { Abdominal pain or discomfort for at least } 12 \text { weeks (not necessarily consecutive) } \\
\text { in the preceding } 12 \text { months with at least two of the following characteristics: } \\
\text { - Eased after defecation; } \\
\text { - Change in the frequency of bowel movements and } \\
\text { - Change in the shape and appearance of feces. }\end{array}$ \\
\hline $\begin{array}{l}\text { Associated symptoms: } \\
\text { 1. < Three bowel movements per week; } \\
\text { 2. > Three bowel movements per day; } \\
\text { 3. Lumpy or hard stools; } \\
\text { 4. Watery stools; } \\
\text { 5. Straining; } \\
\text { 6. Urgency; } \\
\text { 7. Sense of incomplete evacuation; } \\
\text { 8. Mucus discharge; } \\
\text { 9. Abdominal bloating. } \\
\quad>\quad \text { IBS constipation-predominant }=>\text { on e or more of items } 1,3 \text { and } 5\end{array}$ \\
\hline
\end{tabular}

FIGURE 1. Rome II criteria for diagnosis of chronic functional constipation (FC) and irritable bowel syndrome constipation-predominant (IBS)

The clinical assessment was obtained using a specificallydesigned questionnaire filled out by a specialist either in Gastroenterology or Colorectal Surgery that included questions on duration of symptoms, interval between bowel movements (BM), feeling of desire to defecate, strain during defecation, hard stools, feeling of incomplete evacuation, sense of obstructed defecation, abdominal pain and bloating, nausea or vomiting, alternating constipation, fecal impaction, necessity of abdominal or digital manipulation to obtain defecation and use of laxatives and enemas. Patients were also asked about diseases that can cause or predispose to $\mathrm{CC}$ and use of potential constipating drugs. A careful abdominal and rectal examination was carried out with special attention to the presence of spastic pelvic floor and rectocele.

Constipated patients with anal fissure or stricture were excluded. Laboratory tests (glycemia, thyroid hormones and calcemia), barium enema and/or colonoscopy ruled out other secondary causes for constipation, such as endocrine diseases (diabetes, hypothyroidism, and hyperparathyroidism), tumors or other sorts of colonic stricture (diverticulitis, endometriosis, etc). Patients observed with megacolon and/or megarectum on barium enema were tested for Chagas' disease and those with positive results on serology were referred to surgical treatment and excluded from the present study. In addition, patients with neurologic or mental diseases or those in use of potentially constipating drugs (tricycle antidepressants, antipsychotic drugs, calcium canal blockers, anticholinergics, etc) were also ruled out.

All 179 patients were asked to ingest high fiber diet with a supplement of 30 to $40 \mathrm{~g}$ /day of pure fiber (wheat bran) and a minimum of $2000 \mathrm{~mL}$ of water/day. Physical activity was advised, including regular walking and abdominal exercises. Patients were instructed to complete a dietary and defecatory diary in order to have the compliance of such measures checked and to verify the interval between BM. The patients who did not respond to this initial treatment after an interval of 30 to 45 days (still maintaining Rome II criteria for FC or IBS constipation-predominant) were considered refractory and referred to physiologic tests. This diagnostic work-up was established in accordance with American Gastroenterology Association algorithm for refractory chronic constipation $^{(11)}$.

The study was approved by the Ethical Committee for Research of the Federal University of Minas Gerais.

\section{Physiologic tests}

Colonic transit time (CTT). This test was accomplished according to one of following methods: (1) a modified MARTELLI et al. technique ${ }^{(13)}$ consisted in ingestion of 20 radiopaque markers on day 1 and an abdominal plain x-ray was obtained in day 5 . Retention of more than $20 \%$ of markers (four or more markers) along all colonic segments or into an isolated colonic segment was considered abnormal; (2) a modified METCALF et al. technique ${ }^{(15)}$ consisted in ingestion of 20 radiopaque markers on days 1, 2 and 3 of the study and abdominal x-rays taken on days 4 and 7 . Transit in hours at the right, left, and rectosigmoid colon was calculated by adding all markers seen in these regions on days 4 and 7 multiplied by a constant according to the original study of ARHAN et al.(1). Total transit time of more than 68 hours, right colonic transit time of more than 32 hours, left colonic transit time of more than 39 hours and rectosigmoid transit time of more than 36 hours were considered to be abnormal ${ }^{(15)}$. The radiopaque markers were made of thin slices of a long gastrointestinal tube (16-Fr Cantor tube, Rusch Inc., Duluth, Georgia, USA) accommodated into an one-gram gelatin capsule. No laxatives, enemas or suppositories were allowed during the accomplishment of the tests. The following diagnostic categories were considered: (1) colonic inertia when there was right colonic delay; (2) pelvic floor dysfunction when there was isolated rectosigmoid delay or associated rectosigmoid and left colonic delay, and (3) normal transit constipation when CTT was normal ${ }^{(11)}$.

Defecography. This exam consists of a dynamic radiologic study of anorectal function during a simulated defecation ${ }^{(12)}$. A soft barium paste comparable to the fecal consistency was injected into the rectum and the vagina was fulfilled with a barium gel. One hour before, $200 \mathrm{~mL}$ of oral diluted barium was ingested by the patient in order to identify small bowel loops. Evacuation was observed from the start of straining to the completion of rectal emptying which was evaluated to determine completeness 
of contrast evacuation. Diagnostic categories obtained were spastic pelvic floor, internal procidentia, rectocele, enterocele, sigmoidocele and descending perineum.

Anorectal manometry (ARM). This test was performed with a four-channel water perfused catheter using a stationed pull-through technique (Mui Scientific, Mississauga, Ontario, Canada) connected to an electronic manometer and to a computer which generated the graphic register (Sandhill Scientific Inc., Littleton, Colorado, USA). It was investigated the possibility of rectoanal inhibitory reflex (RAIR) absence insufflating 30 to $60 \mathrm{~mL}$ of air in a rectal balloon. In cases of patients with megarectum, increasing volumes were injected in order to try to elicit RAIR. Balloon expulsion test (BET) was performed asking to patient to bearing down a partially filled rectal balloon with observation of the pressure pattern. It was considered abnormal when an elevation of pressure occurred instead of an expected decrease.

Dynamic electromyography of anal sphincter (EMG). This test was performed by inserting an anal plug with concentric electrodes (perry sensor ${ }^{\mathrm{TM}}$, Sandhill Scientific Inc., Littleton, Colorado, USA). Electrical activity was recorded at rest and with patient squeezing and bearing down. Spastic pelvic floor was diagnosed when no decrease of electrical activity was observed during bearing down maneuver.

Initially, CTT was performed in an attempt to identify the pathophysiology of constipation, as a colonic propulsive disturbance or a pelvic floor dysfunction. In this study, we considered that normal colonic transit time ruled out $\mathrm{CC}$ due to colonic inertia but not the possibility of pelvic floor dysfunction, if patient exhibited clinical features of obstructed defecation. Defecography was performed in all patients with isolated rectosigmoid delay, isolated left colonic delay or with association of both on CTT. Patients with normal CTT or with no CTT but with symptoms of pelvic floor dysfunction or suspicion of spastic pelvic floor or rectocele on rectal exam were also undergone to this test. Balloon expulsion test and/or EMG were also performed to confirm spastic pelvic floor suspected on defecography or by clinical assessment with inconclusive defecography. Patients with megacolon underwent ARM to investigate the presence or absence of RAIR. Full-thickness rectal biopsy was performed in patients with no rectoanal inhibitory reflex to confirm or not the diagnosis of Hirschsprung's disease.

\section{Classification of patients}

Patients were classified into five etiologic groups of functional constipation according to Rome II criteria and the results of the physiologic tests, when indicated, as follows: (1) faulty diet and life-style habits, when a good response to initial treatment was reached; (2) pelvic floor dysfunction confirmed by findings on defecography, ARM and/or EMG; (3) colonic inertia confirmed by CTT; (4) non-chagasic megacolon diagnosed by barium enema, ARM and full-thickness rectal biopsy, whenever indicated, and (5) idiopathic functional constipation when patients met Rome criteria for FC and had normal physiologic tests. IBS was diagnosed in patients who met criteria for IBS constipation-predominant according to Rome II and who responded to initial measures or in those with the same criteria who needed physiologic tests and whose results were normal.

\section{Statistics}

The data concerning clinical presentation of constipation and the results of physiologic tests for each group were submitted to comparison using the Kruskal-Wallis test and Mann-Whitney U test whenever appropriate. Comparisons of proportions used the chi-squared test. A $P$ value of $<0.05$ was considered significant. To establish clinical parameters that could predict which constipated patients need physiologic tests to define the etiology of $\mathrm{CC}$, data from patients submitted to these tests were compared with data from patients in which the diagnosis was made based only on clinical data (Rome Criteria and response to dietetic and functional reeducation.). Mann-Whitney $\mathrm{U}$ test and chi-square test were applied and a $P$ value $<0.05$ was considered significant.

\section{RESULTS}

One hundred and forty-nine patients (83\%) were females (mean age $=45.2 \pm 16.55$ ). The duration of symptoms averaged 15.6 years (range, 1-60). Straining (88\%), abdominal bloating $(85 \%)$, feeling of incomplete evacuation $(84 \%)$, hard bowel movements $(81 \%)$, fewer than three BM's per wk $(78 \%)$ and abdominal pain (76\%) were the most common symptoms. Use of laxatives and enemas was reported by $75 \%$ and $26 \%$ of patients, respectively (Figure 2).

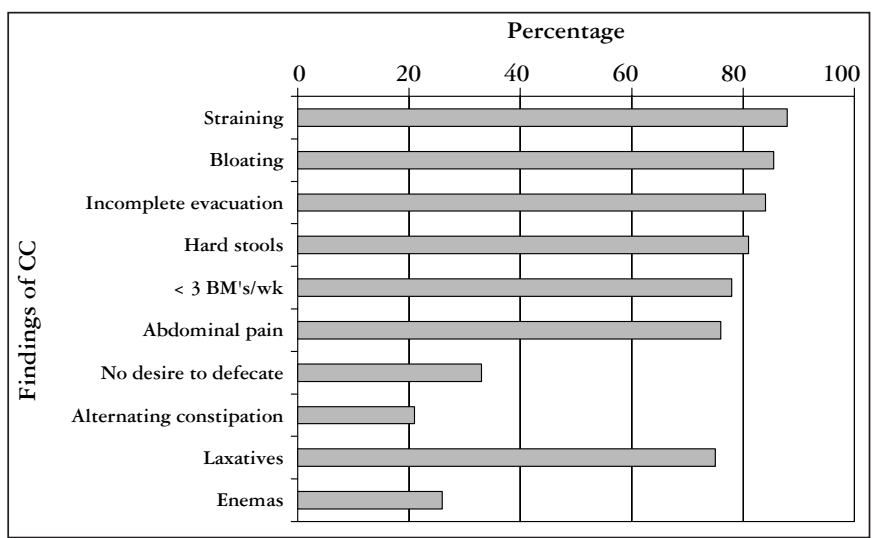

FIGURE 2. Prevalence of symptoms in 179 constipated patients

Sixty-nine patients (38.5\%) had the diagnosis of CC based on clinical assessment and good response to dietary and functional reeducation with diagnoses of IBS $(29 / 69,42 \%)$ or FC due to faulty diet and life style habits $(40 / 69,58 \%)$. Physiologic tests were performed in 110 patients $(61.5 \%)$ who did not respond to the above approach. Colonic transit time and defecography were the most frequently performed tests (Figure 3). In 70 out of 110 patients, physiologic tests were able to clarify the diagnosis. From those, pelvic floor dysfunction was seen in 52 patients $(74 \%)$, colonic inertia in 13 patients (19\%) and non-chagasic megacolon in 5 patients (7\%). The remaining 40 patients have shown no significant alterations on physiologic tests. In these cases, a diagnosis of IBS 


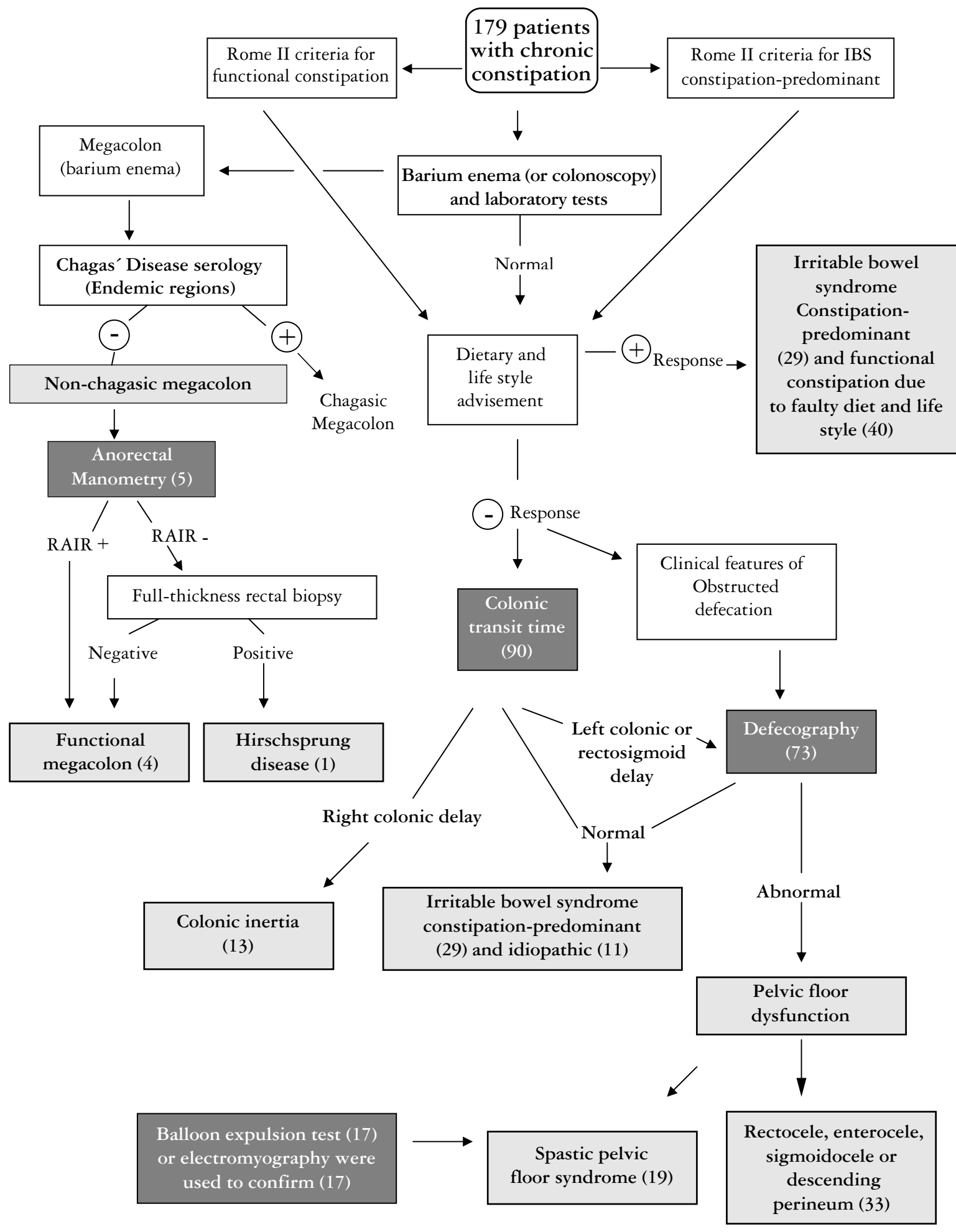

FIGURE 3. Diagnostic algorithm for refractory constipation showing the numbers of patients underwent physiologic tests and the numbers of patients diagnosed according to the etiology of chronic constipation. (RAIR, rectoanal inhibitory reflex; etiologic diagnosis are represented in light grey) 
was confirmed in 29 patients $(72 \%)$ and the diagnosis of idiopathic functional constipation was established in 11 (28\%) (Figure 2). Overall, physiologic testing was necessary to reach an etiologic diagnosis of CC in $63.6 \%$ of patients tested.

The data have shown that IBS was the most common cause of CC (32.4\%) followed by pelvic floor dysfunction cases (29\%) - mainly caused by spastic pelvic floor and rectocele - and by FC due to faulty diet and life style habits $(22.3 \%)$, colonic inertia $(7.3 \%)$ and non-chagasic megacolon (2.7\%). Table 1 depicts

TABLE 1. Etiologic diagnosis in 179 patients with chronic constipation

\begin{tabular}{lcc}
\hline Final diagnosis of chronic constipation & Frequency & $\%$ \\
\hline Irritable bowel syndrome & 58 & 32.4 \\
Pelvic floor dysfunction & 52 & 29.0 \\
$\quad$ Spastic pelvic floor syndrome & $(19)$ & \\
Rectocele & $(15)$ & \\
Internal procidentia & $(7)$ & \\
Rectocele + descending perineum & $(4)$ & \\
Descending perineum & $(2)$ & \\
Enterocele & $(2)$ & \\
Sigmoidocele & $(1)$ & 22.3 \\
Rectocele + enterocele+ descendig perineum & $(1)$ & 7.3 \\
Rectocele + internal procidentia + descending perineum & $(1)$ & 2.7 \\
Faulty diet and life-style habits & 40 & \\
Colonic Inertia & 13 & \\
Non-chagasic megacolon & 5 & 6.1 \\
Psychogenic megacolon & $(4)$ & 100.0 \\
Hirschsprung disease & $(1)$ & \\
Idiopathic Functional Constipation & 11 & \\
Total & 179 & \\
\hline
\end{tabular}

the etiologic diagnosis obtained in all 179 patients and Figure 1 shows how these diagnoses were obtained according to the diagnostic work-up algorithm.

Diagnosis of FC due to pelvic floor dysfunction was significantly related to digital assistance to evacuate $(P<0.01)$ and findings of large rectocele or spastic pelvic floor on rectal exam $(P<0.01$ and $P<0.01$, respectively) (Table 2$)$. A younger age $(P<0.05)$, larger intervals between BM's $(P<0.05)$, occurrence of fecal impaction $(P<0.001)$, and necessity of enema $(P<0.001)$ were associated with diagnosis of non-chagasic megacolon (Table 2). One patient from this group tolerated 1 month without any BM. Alternating constipation $(P<0.01)$ and nausea/vomiting $(P<0.05)$ are $I B S$-related symptoms. Abdominal massage $(P<0.01)$ and bloating $(P<0.01)$ were related to both diagnosis of IBS and colonic inertia. No clinical parameter was significantly related to diagnosis of FC due to faulty diet and life-style or idiopathic functional constipation (Table 2).

Normal colonic transit time was significantly related to the diagnosis of IBS and idiopathic functional constipation $(P<0.01$ and $P<0.01$, respectively). Incomplete elimination of contrast on defecography was related to the $\mathrm{FC}$ due to pelvic floor dysfunction $(P<0.001)$. Normal CTT measurement was observed in 18 of 52 patients $(35 \%)$ found to have pelvic floor dysfunction on defecography, BET or EMG.

Patients undergoing physiologic tests more frequently presented long-standing constipation $(P<0.01)$, fecal impaction $(P<0.05)$, utilization of enemas $(P<0.05)$, digital assistance to defecate, no report of abdominal pain eased after defecation $(P<0.01)$ and large rectocele on pelvic examination $(P<0.01)$, when compared to patients with no need for such tests (Table 3 ).

TABLE 2. Univariate analysis of clinical parameters between 6 groups of patients with chronic constipation

\begin{tabular}{|c|c|c|c|c|c|c|c|}
\hline Clinical findings & IBS & PFD & $\mathrm{FDH}$ & CI & IFC & NCM & $P$ \\
\hline Interval between BM's (days) & $7,4 \pm 5,5$ & $6,2 \pm 4,9$ & $5,8 \pm 4,7$ & $9,8 \pm 7,1$ & $5,5 \pm 4,8$ & $23,8 \pm 21,4 \div$ & $<0,05$ \\
\hline Duration of symptoms & $197,68 \pm 181,61$ & $160,02 \pm 176,99$ & $185,42 \pm 166,03$ & $260,30 \pm 193,02$ & $146,02 \pm 175,65$ & $193,2 \pm 89,6$ & NS \\
\hline No feeling of desire to defecate & $21 / 55$ & $13 / 50$ & $8 / 40$ & $7 / 13$ & $5 / 11$ & $3 / 5$ & NS \\
\hline Excessive straining & $50 / 58$ & $51 / 52$ & $34 / 40$ & $10 / 13$ & $9 / 11$ & $5 / 5$ & NS \\
\hline Sense of incomplete evacuation & $54 / 58$ & $45 / 52$ & $28 / 40$ & $11 / 13$ & $10 / 11$ & $2 / 5$ & NS \\
\hline Abdominal bloating & $57 / 58 \ddagger$ & $39 / 52$ & $32 / 40$ & $13 / 13 \ddagger$ & $9 / 11$ & $4 / 5$ & $<0,01$ \\
\hline Hard stools & $50 / 58$ & $37 / 52$ & $31 / 40$ & $12 / 13$ & $11 / 11$ & $4 / 5$ & NS \\
\hline Mucus discharge & $27 / 58$ & $17 / 52$ & $15 / 40$ & $6 / 13$ & $5 / 11$ & $1 / 5$ & NS \\
\hline Alternating constipation & $24 / 56 \div$ & $7 / 50$ & $2 / 40$ & $2 / 12$ & $2 / 11$ & $0 / 5$ & $<0,01$ \\
\hline Fecal impaction & $12 / 58$ & $13 / 52$ & $4 / 40$ & $1 / 13$ & $1 / 11$ & $5 / 5 \ddagger$ & $<0,01$ \\
\hline Nausea/vomit & $23 / 55 \ddagger$ & $16 / 47$ & $10 / 40$ & $7 / 12$ & $2 / 11$ & $1 / 5$ & $<0,05$ \\
\hline Abdominal massage & $34 / 58 \ddagger$ & $17 / 52$ & $9 / 40$ & $7 / 12 \ddagger$ & $4 / 11$ & $1 / 5$ & $<0,01$ \\
\hline Digital assistance & $21 / 58$ & $32 / 52 \ddagger$ & $10 / 40$ & $3 / 12$ & $4 / 11$ & $2 / 5$ & $<0,01$ \\
\hline Laxative use & $47 / 58$ & $36 / 52$ & $27 / 40$ & $12 / 13$ & $8 / 11$ & $4 / 5$ & NS \\
\hline Enema necessity & $12 / 58$ & $16 / 52$ & $6 / 40$ & $5 / 13$ & $2 / 11$ & $5 / 5 \ddagger$ & $<0,01$ \\
\hline Distention on abdominal examination & $8 / 55$ & $7 / 46$ & $2 / 39$ & $2 / 13$ & $0 / 10$ & $1 / 5$ & NS \\
\hline Pain on abdominal examination & $42 / 55$ & $24 / 46$ & $21 / 39$ & $8 / 13$ & $4 / 10$ & $3 / 5$ & NS \\
\hline Large rectocele on pelvic examination & $5 / 54$ & $18 / 44 \div$ & $1 / 37$ & $0 / 13$ & $1 / 10$ & $0 / 5$ & $<0,01$ \\
\hline $\begin{array}{l}\text { Spastic pelvic floor on pelvic } \\
\text { examination }\end{array}$ & $2 / 54$ & $12 / 44 \ddagger$ & $1 / 47$ & $1 / 13$ & $0 / 10$ & $0 / 5$ & $<0,01$ \\
\hline
\end{tabular}

$\mathrm{IBS}=$ irritable bowel syndrome; $\mathrm{FDH}=$ faulty diet and habits;

$\mathrm{Cl}=$ colonic inertia; IFC = idiopathic functional constipation;

$\mathrm{NCM}=$ non-chagasic megacolon; PFD = pelvic floor dysfunction

NS = not significant

‡ Subgroup of chronic constipation in which clinical feature was significantly more common 
TABLE 3. Results of univariate analysis between patients with chronic constipation underwent physiologic tests $(n=110)$ and patients with no physiologic tests (diagnosis established only on clinical basis) $(\mathrm{n}=69)$

\begin{tabular}{lccc}
\hline Clinical findings & $\begin{array}{c}\text { Patients with } \\
\text { physiologic tests }\end{array}$ & $\begin{array}{c}\text { Patients with no } \\
\text { physiologic tests }\end{array}$ & $P$ \\
\hline Interval between BM's (days) & $7,8 \pm 7,6$ & $6,2 \pm 5,1$ & NS \\
Duration of symptoms & $203 \pm 170,0$ & $162 \pm 82,0$ & $<0,01$ \\
No feeling of desire to defecate & $36 / 110$ & $21 / 69$ & NS \\
Excessive straining & $100 / 110$ & $59 / 69$ & NS \\
Sense of incomplete evacuation & $95 / 110$ & $55 / 69$ & NS \\
Abdominal pain & $83 / 110$ & $53 / 69$ & NS \\
Abdominal pain eased after evacuation & $37 / 80$ & $35 / 49$ & $<0,01$ \\
Abdominal bloating & $93 / 110$ & $50 / 69$ & NS \\
Hard stools & $89 / 110$ & $56 / 69$ & NS \\
Fecal impaction & $28 / 110$ & $8 / 69$ & $<0,05$ \\
Alternating constipation & $21 / 105$ & $16 / 69$ & NS \\
Nausea/vomiting & $38 / 101$ & $21 / 69$ & NS \\
Abdominal massage & $50 / 109$ & $22 / 69$ & NS \\
Digital assistance & $53 / 109$ & $10 / 69$ & $<0,01$ \\
Use of laxative & $86 / 110$ & $48 / 69$ & NS \\
Use of enema & $35 / 109$ & $11 / 69$ & $<0,05$ \\
Distention on abdominal examination & $13 / 100$ & $7 / 68$ & NS \\
Pain on abdominal examination & $59 / 100$ & $43 / 68$ & NS \\
Large rectocele on pelvic examination & $22 / 65$ & $2 / 54$ & $<0,01$ \\
Spastic pelvic floor on pelvic examination & $11 / 69$ & $5 / 87$ & NS \\
\hline
\end{tabular}

\section{DISCUSSION}

The term constipation remains imprecise ${ }^{(5,6,8,9,21)}$. In the present study, the definition of $\mathrm{CC}$ was based upon the Rome II criteria and these, associated to good response to initial dietary and functional reeducation, were able to define $38.5 \%$ of the diagnoses. Few studies have used clinical criteria to classify patients with $\mathrm{CC}^{(4,14,19)}$, but none have used clinical data exclusively to define diagnosis of IBS (Rome or Manning criteria) or functional constipation due to faulty diet and lifestyle habits (Rome criteria). The relatively high proportion of patients with this type of constipation seen in a tertiary center $(22.3 \%)$ reflects failures in diagnostic and therapeutic approaches in primary and secondary care. This fact may express the reality in other specialized centers where many patients with normal physiologic tests have a misdiagnosed idiopathic constipation instead of a simple constipation secondary to faulty diet and life-style habits not properly approached.

Physiologic tests were necessary to clarify the diagnosis of $\mathrm{CC}$ in the majority of patients (110/179 or $61.5 \%)$, but more than one third of these tests (40/110) did not show significant alterations capable of determining an etiology for chronic constipation. Most of these patients fulfilled criteria for IBS, but were undergone to the tests because they exhibited symptoms mainly related to obstructed defecation, a very common feature in IBS (Table 2). These IBS-patients who badly responded to the initial approach with dietary and life-style advises must be observed more strictly before to proceed to physiologic tests. Therefore, taking into account the total number of
179 patients with $\mathrm{CC}$, most of them $(61.5 \%)$ would have the etiologic diagnosis achieved only in clinical basis, comprising those with no need of tests ( 69 patients) and those with normal tests (40 patients).

The contribution of physiologic tests to clarify the etiologic diagnosis of CC varies from $53 \%$ to $92 \%$ in the literature $(4,6,8,21)$. The test data have shown pelvic floor dysfunction $(52 / 110)$ and IBS with normal tests $(29 / 110)$ as the main causes of constipation. However, most of the studies with patients submitted to physiologic tests have described dysfunction of colonic propulsion (colonic inertia) and pelvic floor dysfunction caused by spastic pelvic floor or rectoceles as the main causes of $\mathrm{CC}^{(5,6,12,14,21)}$. The same proportion of patients with IBS confirmed by sensorial and autonomic tests and normal colonic transit time was reported by MERTZ et al. ${ }^{(14)}$. They have shown that $82 \%$ of constipated patients satisfied Rome criteria for IBS, but other diagnoses, such as colonic inertia and pelvic floor dysfunction were found on physiologic tests, suggesting mixed causes of $\mathrm{CC}$.

Difficulties in studying the etiology of CC emerged partially from the discrepancy observed in the literature due to the specificity of investigations performed in specialized centers of gastroenterology or coloproctology ${ }^{(19)}$. Depending on the specialty of the authors, gastroenterologists or colorectal surgeons, the studies may reflect a bias, with motility abnormalities such as IBS being referred mostly by the former ${ }^{(4,8,14,19)}$ and evidence of pelvic floor and anorectal disorders as main causes of chronic constipation, by the latter ${ }^{(9,6,21)}$. As a tertiary center for disorders of defecation with coloproctologists and gastroenterologists working in it, we have taken both constipated patients with motility abnormalities and obstructed defecation referred to evaluation and treatment.

Alternating constipation and nausea or vomiting were symptoms associated with the diagnosis of IBS. Normal colonic transit time was a common finding in these patients ${ }^{(4)}$. Bloating and abdominal massage, usually not mentioned in other studies, are associated with the diagnosis of colonic inertia, despite its association with IBS, as well. Significant association with other clinical findings of colonic inertia, such as history of constipation since childhood, infrequent stools and laxative dependence were not observed, as described by GLIA et al. ${ }^{(4)}$. However, the present data are in accordance with the study of HALVERSON and ORKIN(6), in which the diagnosis of colonic inertia based upon clinical history, was not possible.

Straining and sense of incomplete evacuation were symptoms equally distributed among all groups of CC, being considered unspecific, as observed by others ${ }^{(6,14)}$. Digital assistance to evacuate and large rectocele or spastic pelvic floor, both suspected on rectal examination, were significantly associated with the diagnosis of pelvic floor dysfunction. These alterations were identified only in very careful rectal examination, which is highly recommended during clinical evaluation according to the American Gastroenterological Association Medical Position Statement: guidelines on constipation ${ }^{(11)}$. 
Incomplete elimination of contrast on defecography was also significantly related to the diagnosis of pelvic floor dysfunction and may be considered of paramount importance, inasmuch as many rectoceles found on physical examination do not cause, by themselves, difficulties in contrast elimination during defecography ${ }^{(6)}$. Conversely, CTT measurement was not able to confirm pelvic floor dysfunction in $35 \%$ of patients tested with this diagnosis, as previously demonstrated by others ${ }^{(4,5)}$. Most of patients with pelvic floor dysfunction and normal CTT were able to have a $\mathrm{BM}$ three times or more in a week, but with great straining and use of digital assistance. That was the reason we proceeded to defecography in patients with symptoms of obstructed defecation and normal CTT. Therefore, defecography has been considered very useful to identify causes of constipation due to pelvic floor dysfunction in patients with chronic constipation ${ }^{(6)}$ in opposition to clinical history or CTT.

One more subgroup of functional constipation patients characterized by megacolon with negative serologic tests for Chagas' disease was included in the present study. Most of these cases have been diagnosed as adult Hirchsprung's disease, in other studies ${ }^{(2,3)}$. However, only one of our five megacolon patients had this diagnosis confirmed by fullthickness rectal biopsy (Figure 3). The others were classified as functional megacolon, also named psychogenic megacolon, a condition which has been reported in adolescent and young adults as a result of a long-standing fecal retention caused, most of the time, by an early and coercive toilet training obligated by obsessive mothers ${ }^{(16)}$. Younger ages at diagnosis, larger intervals between BM's, fecal impaction and necessity of enema were symptoms significantly associated with the diagnosis of megacolon. Large intervals between BM of up to 2 months have been described in patients with condition ${ }^{(2)}$, which implies the continuous necessity of enemas in these patients. In Brazil, it is mandatory to rule out the possibility of Chagas' disease in all constipated patients with megacolon, because of the prevalence of this disease in some endemic regions in our country.

It has been stated that all patients with severe chronic constipation refractory to initial dietary and functional management should undergo colorectal physiological tests ${ }^{(6,10,11,21)}$. This statement may be a questionable point because the costs of investigation of chronic constipation are increasing without a clear benefit in many patients ${ }^{(17)}$. This study may contribute to this topic, as it points out some useful clinical parameters which were capable of helping with the indication of physiological tests to better define the etiology of CC, such as long-standing constipation, fecal impaction, necessity of enemas, digital assistance to defecate, abdominal pain not eased after defecation, and large rectocele on pelvic examination. These clinical features have drawn attention to the diagnosis of severe functional disease, related to pelvic floor dysfunction, colonic inertia or megacolon instead of IBS, a very confusing condition which sometimes demands physiologic tests. In patients with these symptoms, a precise investigation with physiologic tests may confirm such diagnoses of $\mathrm{CC}$ and contribute to alleviate the symptoms of patients by means of specific treatments.

Lacerda-Filho A, Lima MJR, Magalhães MF, Paiva RA, Cunha-Melo JR. O papel da avaliação clínica e dos testes de fisiologia colo-reto anal no diagnóstico etiológico da constipação intestinal crônica. Arq Gastroenterol. 2008;45(1):50-7.

RESUMO - Racional - O diagnóstico dos subtipos de constipação crônica tem sido considerado difícil de ser estabelecido, mesmo em centros especializados. Embora os testes fisiológicos tenham trazido uma importante contribuição, ainda há dúvidas quanto as suas indicações. Objetivos - Estabelecer o diagnóstico diferencial em casos de constipação crônica através da avaliação clínica e da utilização de testes fisiológicos, procurando-se identificar parâmetros clínicos que poderiam predizer quais pacientes necessitariam de tais testes. Métodos - Cento e setenta e nove pacientes ( $83 \%$ do sexo feminino; média de idade de 45 anos) com constipação crônica de acordo com os critérios de Roma II foram inicialmente tratados com medidas dietéticas e reeducação funcional e aqueles que não responderam (110 ou 61,5\%) foram submetidos a tempo de trânsito colônico, defecografia, manometria anorretal e eletromiografia, de acordo com apresentação clínica da constipação crônica. Resultados - O diagnóstico etiológico foi obtido em $63.6 \%$ dos pacientes testados. Entretanto, em $61,5 \%$ (69 que não necessitaram dos testes e 40 que tiveram testes normais), o diagnóstico etiológico foi estabelecido em bases clínicas. A síndrome do intestino irritável (32\%), a disfunção do assoalho pélvico (29\%) e a constipação funcional secundária a inadequação dietética e de hábitos de vida (22\%) foram os principais diagnósticos etiológicos da constipação crônica. A alternância de constipação e a presença de náuseas/vômitos estiveram significativamente relacionadas ao diagnóstico de síndrome do intestino irritável; idade precoce, grandes intervalos entre as evacuações, ocorrência de impactação fecal e necessidade de enemas estiveram relacionadas ao diagnóstico de megacólon não-chagásico, enquanto assistência digital para evacuar e grande retocele ou assoalho pélvico espástico ao toque retal se associaram à disfunção do assoalho pélvico. Pacientes com constipação de longa duração, impactação fecal, dor abdominal não aliviada pelas evacuações, necessidade de enemas, assistência digital para evacuar e com evidência de retocele tendem a necessitar de testes de fisiologia para definição da causa de constipação crônica. Conclusões - O diagnóstico etiológico da constipação crônica pode ser obtido na maioria dos pacientes somente em bases clínicas, sendo que alguns sintomas estão significativamente associados a determinados diagnósticos. A indicação dos testes de fisiologia, por sua vez, deve ser baseada em parâmetros clínicos específicos.

DESCRITORES - Constipação intestinal. Síndrome do intestino irritável. Defecação. Trânsito gastrointestinal. 


\section{REFERENCES}

1. Arhan P, Devroede G, Jehannin B, Lanza M, Faverdin C, Dornic C, Perzon B, Tetreault L, Perey B, Pellerin D. Segmental colonic transit time. Dis Colon Rectum. 1981;24:625-9.

2. Barnes PRH, Lenard-Jones JE, Hawley PR, Todd IP. Hirschsprung's disease and idiopatihic megacolon in adults and adolescents. Gut. 1986;27:534-41.

3. Gattuso JM, Kamm MA. Clinical features of idiopathic megarectum and idiopathic megacolon. Gut. 1997;41:93-9.

4. Glia A, Lindberg G, Nilsson LH, Mihocsa I, Akerlund JE. Clinical value of symptom assessment in patients with constipation. Dis Colon Rectum. 1999;42:1401-10.

5. Grotz RL, Pemberton JH, Talley NJ, Rath DM, Zinsmeister AR. Discriminant value of psychological distress, symptom profiles, and segmental colonic dysfunction in outpatients with severe idiopathic constipation. Gut. 1994;35:798-802.

6. Halverson AL, Orkin BA. Which physiologic tests are useful in patients with constipation? Dis Colon Rectum. 1998;41:735-9.

7. Johanson JF, Sonnemberg A, Koch TR. Clinical epidemiology of chronic constipation. J Clin Gastroenterol. 1989;11:525-36.

8. Koch A, Voderholzer WA, Klauser AG, Muller-Lissner S. Symptoms in chronic constipation. Dis Colon Rectum. 1997;40:902-6.

9. Kuijpers HC. Application of the colorectal laboratory in diagnosis and treatment of functional constipation. Dis Colon Rectum. 1990;33:35-9.

10. Lembo A, Camilleri M. Chronic constipation. N Engl J Med. 2003;349:1360-8.

11. Locke GR, Pemberton JH, Phillips SF. American Gastroenterological Association medical position statement: guidelines on constipation. Gastroenterology. 2000;119:1761-78.
12. Mahieu P, Pringot J, Bodart P. Defecography II. Contribution to the diagnosis of defecation disorders. Gastrointest Radiol. 1984;9:253-61.

13. Martelli H, Devroede G, Arhan P, Duguay C, Dornic C, Faverdin C. Some parameters of large bowel motility in normal man. Gastroenterology. 1978;75:612-8.

14. Mertz H, Naliboff B, Mayer EA. Symptoms and physiology in severe chronic constipation. Am J Gastroenterol. 1999;94:131-8.

15. MetcalfAM, Phillips SF, Zinsmeister AR, MacCarty RL, Beart RW, Wolff BG. Simplified assessment of segmental colonic transit. Gastroenterology. 1987;92:40-7.

16. Nurcombe B. Psychogenic megacolon. The study of a psychosomatic relationship. Med J Aust. 1972;18:1178-82.

17. Rantis PC Jr, Vernava AM 3rd, Daniel GL, Longo WE. Chronic constipation - is the work-up worth the cost? Dis Colon Rectum. 1997;40:280-6.

18. Sandler RS, Drossman DA, Nathan HP, McKee DC. Symptom complaints and health care seeking behavior in subjects with bowel dysfunction. Gastroenterology. 1984;87:314-8.

19. Surrenti E, Rath DM, Pemberton JH, Camilleri M. Audit of constipation in tertiary referral gastroenterology practice. Am J Gastroenterol. 1995;90:1471-5.

20. Thompson WG, Longstreth GF, Drossman DA, Heaton KW, Irvine EJ, MullerLissner SA. Functional bowel disorders and functional abdominal pain. Gut. 1999;45 (Suppl 2):43-7.

21. Wexner SD, Jorge JMN. Colorectal physiological tests: use or abuse of technology? Eur J Surg. 1994;160:167-74. 